\title{
O MARKETING DE
}

\section{RELACIONAMENTO: O NOVO}

\section{MARKETING DA NOVA ERA COMPETITIVA}

\author{
Paulo Eduardo Sallby \\ E-mail:psaliby@ibm.net
}

\section{O NOVO CONTEXTO EMPRESARIAL}

$\mathrm{O}$ ambiente empresarial mundial vem sendo palco de transformações cada vez mais rápidas, bruscas e expressivas na forma de se fazer negócios. Em um momento como esse, as empresas devem, como medida de sobrevivência, aumentar sua produtividade e competitividade.

A nova era competitiva foi assim caracterizada por Regis McKenna: ${ }^{1}$

- crescente diversidade de produtos e serviços;

- crescente concorrência global;

- segmentação de mercados, tecnologias e soluções;

- mudanças organizacionais e estruturais nas empresas, buscando novas maneiras de administrar os negócios;

- canais de distribuição que estão em constante movimento. Ainda que estar próximo do cliente seja preponderante, os canais frequien- temente negligenciam o diálogo com o cliente;

- mídias tradicionais ampliam o nível de ruído e falham em comunicar claramente as mensagens. A confusão reina;

- o ambiente de negócios e o cenário futuro da competitividade são imprevisíveis;

- previsões de pesquisas de mercado não fornecem um rumo claro para as ações.

O que é fundamental que os empresários compreendam é que os clientes estão se tornando cada vez mais exigentes e, diferentemente dos clientes de dez anos atrás, eles querem cada vez mais qualidade e menos preço. $O$ aumento das exigências, por parte dos clientes, pode ser facilmente explicado pela crescente diversidade e quantidade de produtos e serviços ofertados e pela crescente concorrência global.

Os grandes avanços ocorridos na tecnologia da informação também colaboraram muito para a formação do quadro atual do mundo dos negócios. Agora, uma pessoa pode, através da internet, consultar inúmeros preços de produtos/serviços de várias empresas em tempo real e a um custo muito baixo. Portanto, o cliente está melhor informado e quer comprar simplesmente o que há de melhor no mercado.

O mercado, por sua vez, está cada vez com menos fronteiras, cada vez mais globalizado. Esse fato aumenta ainda mais a concorrência e exige das empresas uma postura muito competitiva, para que possam fazer frente a concorrentes do mundo inteiro e satisfazer clientes do mundo inteiro.

$O$ aumento da competição e os avanços tecnológicos geraram mudanças radicais na estrutura das empresas, que está cada vez mais horizontal e enxuta. A palavra de ordem tem sido flexibilidade. As empresas e seus empregados tiveram que aprender a conviver com as mudanças e com a imprevisibilidade do amanhã, o que não tem sido fácil, tanto que muitas 
empresas fecharam as suas portas e muitas ainda irão fechar.

A sociedade está passando por uma alteração significativa em seus valores, cabendo aos homens de negócio entender essas mudanças e evoluir a maneira de se administrar os empreendimentos.

Stan Rapp ${ }^{2}$ identificou, em seu livro $5^{a} g e-$ ração do marketing: maximarketing $I I$, sete fatores causadores de mudança no ambiente empresarial. São eles:

1. Demografia e estilos de vida mutantes: os consumidores não estão mais alinhados como grandes grupos-alvo, simples e previsíveis.

2. As exigências do tempo pessoal: os consumidores estão reconhecendo o valor do tempo, mudando os hábitos de consumo, os valores e suas necessidades.

3. Excesso de novos produtos, serviços e lojas, saturando o consumidor com uma proliferação atordoante de opções de produto: há uma saturação de lojas populares, ao mesmo tempo em que ocorre um aumento na precisão de alvo das lojas especializadas.

4. O enfraquecimento da mágica da propaganda de televisão: existe um declínio do domínio das redes de TV no cenário da propaganda, enquanto que as tarifas continuam subindo e os consumidores mentalmente se desligam dos comerciais.

5. O declínio da lealdade à marca: as promoções e descontos, além da falta de diferenciação aos olhos dos clientes, estão levando à compra por oferta.

6. Desperdício, morte e bagunça na propaganda: há um desafio para a propaganda: encontrar novas soluções criativas e de mídia para atingir os prospects e obter a resposta desejada.

7. Alimentando o monstro da promoção de desconto: o excesso de promoções, descontos e cupons desgasta a lealdade à marca e leva a uma subida temporária e dispendiosa das vendas; consumidores compram pelo desconto e não pela marca.

\section{O MARKETING DE RELACIONAMENTO}

\section{Conceituação}

O marketing de relacionamento surge, portanto, como uma nova abordagem de marke- ting para a nova era competitiva. Seu conceito está ligado à idéia de que irão prosperar, no novo ambiente empresarial, as empresas que tiverem a capacidade de satisfazer os seus clientes e conquistar a fidelidade destes. Mas, para tanto, é necessário que as empresas conheçam e estejam profundamente conectadas com o mercado e com os seus clientes.

$\mathrm{Na}$ abordagem do marketing de relacionamento, os clientes deixam de ser apenas números ou marketshare e passam a ser parte integrante da organização. Seu conceito está ligado à idéia de "trazer o cliente" para dentro da organização, de maneira que ele participe do desenvolvimento de novos produtos/serviços e crie vínculos com a organização. Dessa forma, com o suporte da tecnologia de informação, é possível testar idéias de novos produtos/serviços diretamente com os clientes e em tempo real.

São os clientes que alimentam a empresa, que pagam indiretamente os salários de todos os funcionários da empresa e o retorno dos acionistas. Portanto, é muito natural a idéia de integrar os clientes à organização, de forma que todos os funcionários da organização conheçam muito bem os seus clientes, que compreendam suas necessidades e que saibam que são eles que pagam os seus salários e não a tesouraria da empresa.

Porém, para "trazer" os clientes para dentro da organização, é necessário possuir meios de comunicação dinâmicos e eficazes, que sejam capazes de estimular a interatividade entre o cliente e a empresa $e$ permitir o profundo conhecimento do cliente. É fundamental, portanto, que sejam despendidos muita atenção e recursos nas interações com os clientes.

$\mathrm{O}$ marketing de relacionamento permite, portanto, que a empresa desenvolva uma habilidade no que se refere a compreender o mercado e a saber aprender do mercado. A partir disso, a organização precisa disseminar esses conhecimentos por toda a sua extensão e planejar, criar, inovar e atuar em sintonia com um mercado que é cada vez mais dinâmico $e$ competitivo.

Esse tipo de marketing pode ser interpretado como um investimento feito pela empresa em seus clientes, visando como retorno atingir a satisfação e a fidelidade destes 
e, por conseqüência, prosperidade e lucros altos para a organização.

Segundo Bretzke, ${ }^{3}$ o marketing de relacionamento é: "Uma filosofia de administração empresarial, baseada na aceitação da orientação para o cliente e para o lucro por parte de toda a empresa e no reconhecimento de que se deve buscar novas formas de comunicação para estabelecer um relacionamento profundo e duradouro com os clientes, prospects, fornecedores $e$ todos os intermediários, como forma de obter uma vantagem competitiva sustentável."

Portanto, esse conceito não se refere apenas ao relacionamento com os clientes, mas sim com todos aqueles que possam influenciar na satisfação dos clientes, tais como: revendedores, distribuidores, fabricantes de periféricos etc.

Segundo McKenna, ${ }^{4}$ a prática desse tipo de marketing deve se apoiar no conhecimento e na experimentação: " $O$ marketing baseado no conhecimento exige da empresa uma escala de conhecimento: da tecnologia pertinente; da concorrência; de seus clientes; das novas fontes de tecnologia que podem alterar o ambiente competitivo; e de sua própria organização, recursos, planos e formas de fazer negócios".

O marketing baseado na experiência enfatiza a interatividade, conectividade e criatividade. Com esta abordagem as empresas dedicam-se aos seus clientes, monitoram constantemente seus concorrentes e desenvolvem um sistema de análise de feedback que transforma essa informação sobre o mercado e a concorrência em uma nova e importante informação sobre o produto.

\section{DATABASE MARKETING}

O termo database marketing é frequientemente confundido com marketing de relacionamento, porém a distinção é clara e fácil de ser feita. O database marketing é uma ferramenta, uma técnica à disposição do administrador de marketing, enquanto que o marketing de relacionamento é uma filosofia, uma nova maneira de fazer negócios. Ele compreende o database marketing, porém esse não esgota de forma alguma o conteúdo do rico conceito de marketing de relacionamento.
Database marketing refere-se ao marketing que é feito com base em banco de dados e foi deste termo que se derivou o marketing de relacionamento, que seria um estágio avançadíssimo daquele. Para que o marketing com ação apoiada no uso de banco de dados seja essencialmente de relacionamento, é preciso que sua atuação seja integradora, no sentido de ligar intimamente todas as áreas funcionais da organização aos desejos e necessidades dos clientes.

Quanto à abrangência do database marketing, Stacey ${ }^{5}$ afirma: "Database marketing deve ser usado como uma ferramenta gerencial, como se usa uma calculadora. (...) É a representação eletrônica do universo do seu marketing. (...). É verdade que database marketing não é o Santo Graal. Mas o que ocorre é que ele é a mais nova e eficaz ferramenta de marketing disponível."

Stan Rapp ${ }^{6}$ situou da seguinte forma o database marketing: "Para empresas engajadas no marketing direto $e$ vendas pessoais, o surgimento do database de compradores tem sido mais uma evolução do que uma revolução (...) anteriormente era conhecida como a lista de compradores (...) mas o que transformou a lista de compradores num database foi a habilidade exclusiva do computador de armazenar, ou encontrar, outros bits de informações sobre os compradores, além de seus nomes $e$ endereços (...) um database de compradores é a força mais potente do marketing, desde o surgimento da televisão."

Portanto, enquanto o database marketing possui um caráter mais evolucionário, o marketing de relacionamento apresenta um caráter mais revolucionário.

$S_{\text {chell }}^{7}$ relacionou esses dois tipos de marketing da seguinte forma: “(...) a década de 90 será a década do cliente ou a década da satisfação e serviço do cliente. Desde que o database marketing colocou a ênfase no ciclo de vida do cliente $e$ na sua fidelização, como contrário a serviços de atendimento para clientes anônimos e desconhecidos, o melhor termo para database marketing é provavelmente marketing de relacionamento, que tem se tornado mais e mais popular."

Segundo Ribeiro, ${ }^{8}$ as características da prática do database marketing são: 
1. Permite o diálogo com o cliente através dos meios que se utilizam para o feedback, tais como: a análise dos padrões de feedback e dos históricos de compras, análise das cartas dos clientes, pesquisas etc.

2. Viabiliza 0 aprofundamento na base de clientes. Programas de continuidade, de afinidade, de aumento de volume de vendas tais como: venda cruzada ou intensificação do volume, valor ou frequiência da compra.

3. Permite trabalhar nichos de mercado com eficiência e lucro. Através das informações do banco de dados é possível encontrar nichos de mercado e viabilizar a atuação nesses nichos vencendo a barreira do tamanho do mercado e perda de economia de escala.

4. Oferece maior controle sobre o canal de distribuição. Oferecendo melhores informações sobre o público-alvo e permitindo melhor adequação da oferta.

5. O marketing é mais contabilizado. Trata-se da capacidade de mensurabilidade do sistema e da capacidade do controle das variáveis que influenciam as respostas.

\section{PROGRAMAS de FIDELIZAÇÃo}

Dentro da filosofia do marketing de relacionamento e considerando-se as características da nova era competitiva, os programas de fidelização de clientes devem estar no centro da gestão empresarial contemporânea.

Vale ressaltar que compras repetidas, baseadas em descontos e ofertas, não representam o conceito de fidelização. Estimular a repetição da compra através de um círculo vicioso de desconto e promoções faz com que os consumidores comprem o produto ou serviço por razões alheias à qualidade do produto/serviço.

Para construir a fidelização é essencial entender as necessidades, desejos e valores dos clientes, para depois traçar uma estratégia adequada de fidelização de clientes.

As regras básicas, segundo Stan Rapp, ${ }^{9}$ para a fidelização de clientes são:

1. Desenvolver um ciclo de comunicação com o cliente.

2. Fazer coisas juntos (por exemplo, clube de afinidades).

3. Ouvir cuidadosamente.
4. Pesquisar respeitosamente.

5. Descobrir a força da propaganda de resposta direta.

Segundo Bretzke, ${ }^{10}$ os programas de relacionamento geralmente utilizam as formas abaixo relacionadas:

1. Clubes de clientes.

2. Seminários de clientes.

3. Patrocínio de usuários.

4. Publicações dirigidas aos clientes:

- Newsletters

- Revistas

- Vídeos

- Áudios

- Disquetes

5. Cartões de crédito e/ou condições especiais de crédito.

6. Privilégios adicionais a empresas.

7. Atendimento telefônico de pedidos 24 horas.

8. Atendimento telefônico de assistência 24 horas.

9. Descontos especiais.

10.Garantia de preços mais baixos.

\section{APLICABILIDADE DO MARKETING DE RELACIONAMENTO}

Implantar um modelo de marketing de relacionamento na organização não é recomendável. É um caminho que compensa nos casos em que os clientes têm alto valor para a empresa ao longo de toda a vida. A Boeing Aircraft, por exemplo, deve adotar o marketing de relacionamento porque só pode vender seus aviões para um número muito limitado de pessoas. A General Foods, ao contrário, que vende mercadorias como café para milhões de consumidores com uma margem pequena em cada transação, não poderia partir para esse tipo de marketing.

É altamente recomendável sua aplicação nas empresas business-to-business e na maioria das empresas de serviços.

Nas empresas de médio e pequeno porte, o marketing de relacionamento pode compensar a falta de economia de escala, na medida em que a empresa pode oferecer produtos/serviços mais personalizados, que justifiquem um preço maior e possibilitem às médias e pequenas empresas trabalhar com margens maiores do que as das grandes empresas. 
Muito tem sido pesquisado a seu respeito nas organizações de serviços. Serão abordados alguns desses estudos no próximo item.

\section{O MARKETING DE RELACIONAMENTO NAS EMPRESAS DE SERVIÇOS}

Christian Grönroos ${ }^{11}$ prega que a natureza dos negócios de serviço é baseada no relacionamento. Um serviço é um processo ou performance que envolve o cliente por períodos de tempo variáveis (longo, médio ou curto) e, em alguns casos, por um único encontro, algumas vezes por um longo período de tempo, algumas vezes por um período de tempo médio, algumas vezes por um curto período de tempo, e outras vezes por um único encontro. Sempre há um contato direto entre o cliente e a empresa provedora do serviço e esse contato é o que possibilita que a lealdade do cliente seja conquistada.

Apesar do relacionamento ser da natureza dos negócios de serviço, há casos em que nenhum relacionamento pode ser estabelecido. Como, por exemplo, um viajante que teve problemas em seu carro no meio da noite e resolve passar a noite em um hotel de estrada em que nunca esteve antes e ao qual nunca espera voltar. Nesse caso não é lucrativa uma aproximação de relacionamento, sendo mais indicada a estratégia do marketing transacional tradicional, que visa fazer com que o viajante escolha o hotel em questão.

Pode-se definir como o objetivo do marketing transacional conseguir novos clientes, enquanto que o objetivo do marketing de relacionamento pode ser sintetizado como manter os clientes. O foco na manutenção dos clientes vem ganhando mais força ultimamente, porque se percebeu que é muito mais barato fazer com que um cliente antigo passe a comprar mais do que conseguir um cliente novo.

Ainda segundo Grönroos, ${ }^{12}$ a melhor solução para as empresas é adotar, como estratégia, um mix desses dois tipos de marketing, dando um peso relativo para cada um deles que seja coerente com a natureza dos contatos com os clientes. De forma que, quanto maior o relacionamento com o cliente, permitido pela natureza e circunstância do serviço, mais a estratégia deve tender para o marketing de relacionamento.
Segundo Leonard T. Berry, ${ }^{13}$ a maturidade que vem sendo alcançada pelo marketing de serviços, tanto no que diz respeito à prática quanto à pesquisa, vem levando a um só caminho: ao marketing de relacionamento. A busca pela qualidade na prestação de serviços vem se orientando pela satisfação do cliente $e$ pela conquista da lealdade do mesmo.

Seu desenvolvimento é capaz de trazer inúmeros benefícios para a empresa. Várias pesquisas demonstram que melhorias na qualidade do serviço prestado ao cliente como, por exemplo, diminuição da taxa de erro nos serviços prestados, aumentam em muito o lucro obtido pelas empresas.

Inúmeros benefícios para os clientes também são trazidos pelo desenvolvimento do marketing de relacionamento. Já que as suas necessidades passam a ser mais atendidas, lhes é destinada maior atenção e os serviços ficam mais personalizados e de maior qualidade.

Os avanços tecnológicos, sobretudo na tecnologia das informações, tornaram mais viável e mais eficiente o seu desenvolvimento. Esse avanço permitiu registrar os padrões de comportamento dos clientes, aumentar os canais de comunicação com clientes e fornecedores, personalizar os serviços prestados e minimizar a probabilidade de erros.

Muitas perspectivas novas e interessantes vêm sendo pesquisadas acerca do marketing de relacionamento, dentre elas destacando-se três:

\section{A busca por clientes lucrativos:}

Alguns clientes proporcionam um ganho maior para a empresa do que outros; alguns clientes são tipicamente mais fiéis, enquanto outros não vacilam em passar a comprar serviços de outra empresa devido apenas a uma pequena vantagem.

O marketing de relacionamento deve agir no sentido de atrair, manter e solidificar o relacionamento com os clientes. Isso exige investimento, portanto, passa a ser fundamental a questão da escolha dos clientes certos para investir.

Para descobrir os clientes certos, ou seja, os mais aptos a criarem laços fortes com a empresa, devem ser feitas pesquisas para descobrir as características dos clientes mais fiéis que a empresa possui, descobrir que tipo de profissão têm, onde moram, quais as suas ca- 
racterísticas familiares, etc. Após essa pesquisa, a empresa já sabe em que tipo de cliente ela deve investir.

\section{Vários níveis de marketing de re- lacionamento:}

Este tipo de marketing pode ser praticado em diversos níveis de profundidade. Vários tipos de profundidade podem ser identificados. Para simplificar, divididos em três níveis, temos:

a) Nível 1: nesse nível apenas são utilizados incentivos de preço para manter os clientes. Essa estratégia é muito limitada, pois incentivos de preço são facilmente copiados pelas empresas rivais e, além do mais, consumidores que compram serviços de uma empresa por vantagens de preço facilmente irão comprar de uma outra empresa caso seja vantajoso financeiramente.

b) Nível 2: nesse nível as empresas trabalham com a personalização do relacionamento como, por exemplo, chamar o cliente pelo nome durante $o$ atendimento, fazer com que os clientes sejam atendidos sempre pelo mesmo funcionário, comunicar-se com os clientes através de variados meios, organizar eventos etc.

c) Nível 3: nesse nível a solução do problema do cliente é criada dentro do sistema da empresa, ao invés do relacionamento com o cliente depender exclusivamente dos conhecimentos do funcionário, que pode vir a deixar a empresa. Dessa forma o relacionamento com o cliente é todo registrado em memória eletrônica, de forma que os padrões de comportamento e as preferências dos clientes sejam sempre do conhecimento da empresa.

\section{Marketing de relacionamento interno:}

$\mathrm{O}$ marketing interno tem sido enfatizado na literatura sobre marketing de serviços, devido ao fato de que a prestação de um serviço é um ato cujos atores são os funcionários da empresa. Portanto é fundamental que estes estejam motivados e envolvidos com a satisfação do cliente.

Muitos trabalhos apontam a retenção dos funcionários como um pré-requisito para a retenção dos clientes. Visto que uma elevada rotatividade desencoraja os administradores a investirem em treinamento e compromete a motivação dos funcionários, es- ses dois fatos, por sua vez, comprometem a performance dos funcionários na prestação do serviço. Tem sido argumentado também que os funcionários que já estão há mais tempo na empresa são os mais aptos a servir bem ao cliente, pois eles conhecem mais o negócio e possuem uma maior confiança depositada pelos clientes em relação aos funcionários mais novos.

\section{4) A confiança como uma ferramenta poderosa:}

A confiança vem sendo apontada em muitos estudos como uma das ferramentas mais poderosas de marketing de relacionamento que as empresas possuem a seu dispor. A empresa deve se mostrar confiável para os clientes. Para tanto ela deve:

a) possuir canais de comunicação abertos e transparentes com os clientes;

b) oferecer garantias da qualidade do serviço; c) demonstrar uma conduta correta e ética.

Segundo Bitner, ${ }^{14}$ relacionamentos de longa duração com empresas de serviços podem trazer maior bem-estar e qualidade de vida para os clientes, pois podem diminuir o stress destes na medida em que já é sabido o que se pode esperar da prestação do serviço. Isso é particularmente verdade em serviços complexos (legais, médicos, educação), serviços que envolvem o ego dos clientes (programas de perda de peso, limpeza de pele, corte de cabelo) e em serviços financeiros.

Depois de um certo período de tempo, os consumidores sentem-se mais confortáveis, no que diz respeito ao relacionamento com a empresa provedora, e mais confiantes na empresa. Isso é um grande benefício, já que simplifica a vida dos clientes, diminuindo o número de decisões importantes a serem tomadas e, por conseguinte, diminuindo a possibilidade de arrependimento e de frustração.

Parasuraman, Zeithml e Berry, ${ }^{15}$ desenvolveram um modelo no qual definem cinco hiatos da qualidade na prestação do serviço. Esse modelo realça a importância da administração das expectativas do cliente quanto à qualidade do serviço $\mathrm{e}$, conseqüentemente, quanto à lealdade do cliente. Os hiatos são os seguintes:

Gap 1: Falha na comparação entre a expectativa do consumidor e a percepção gerencial. Nesse caso a gerência especifica 
ações diferentes daquelas esperadas e desejadas pelos clientes.

Gap 2: Falha entre a percepção gerencial e a especificação da qualidade do serviço. Aquilo que a gerência percebe como importante não é traduzido em operações adequadas do ponto de vista do cliente.

Gap 3: Falha na comparação entre a especificação e a prestação do serviço.

Gap 4: Falha na comparação entre a prestação do serviço e a comunicação externa com o cliente.

Gap 5: Falha na comparação entre a expectativa do cliente e a percepção do cliente.

Parasuraman ${ }^{16}$ sugere também que, para conquistar a lealdade do cliente, a organização deve: (1) assegurar que as promessas quanto ao serviço a ser prestado reflitam a realidade; (2) valorizar a confiabilidade prestando o melhor serviço da primeira vez; (3) tornar-se excelente no processo de prestação do serviço aproveitando todas as oportunidades para superar as expectativas dos clientes; (4) recuperar a confiança perdida fazendo o melhor serviço em uma segunda oportunidade e comunicar-se com os clientes.

\section{CONCLUSĀO}

Podemos concluir que o marketing de relacionamento surge como uma nova maneira de se fazer negócios, como uma nova filosofia empresarial, como uma nova forma de se praticar marketing e como um importante elemento da gestão empresarial na nova era competitiva global.

As empresas que não incorporarem a essas novas idéias, sobretudo as empresas do business-to-business $\mathrm{e}$ as do setor de serviços, não conseguirão prosperar no novo ambiente econômico.

No mercado de serviços, muito já tem sido pesquisado e praticado no que diz respeito ao marketing de relacionamento. Porém, no mercado business-to-business, há poucos estudos acerca desse tipo de marketing, destacandose $\mathrm{o}$ artigo The relationship marketing process: a conceptualization and application, escrito por Joel R. Evans e Richard L. Laskin, que apresenta uma aplicação prática de um modelo de marketing de relacionamento no setor industrial.

\section{Notas:}

1. McKENNA, Regis. Relationship marketing: successful strategies for the age of the customer. 1 ed. New York: Addison-Wesley Publishing Company, nov. 1991.

2. RAPP, Stan, COLLINS, Tom L. 5' geração do marketing: maximarketing II. São Paulo: McGraw Hill, 1991.

3. BRETZKE, Miriam. O marketing de relacionamento: integração entre informática e marketing na busca da vantagem competitiva. Dissertação apresentada ao curso de pós-graduação da FGV/EAESP, São Paulo, 1992.

4. MCKENNA, Regis. Marketing de relacionamento: estratégias bem sucedidas para a era do cliente. Rio de Janeiro: Campus, 1993

5. STACEY, Robert T. Database Marketing: Fact or Fact? The Saga Continues. Direct Marketing, v. 53 (4), ago. 1990.

6. RAPP, Stan, COLLINS, Tom L. Op. cit.

7. SCHELL, Ernest $H$. Lifetime value of a customer. Dataline: DMA, v. 6, jan. 1991.

8. RIBEIRO, Áurea H. P. Marketing de relacionamento como sistema contínuo de aprendizado organizacional. São Paulo: s.n., 1995.

9. RAPP, Stan \& COLLINS, Tom L. Op. cit.

10. BRETZKE, Miriam. Op. cit.

11. GRÖNROOS, Christian. Relationship marketing: the strategy continuum. Journal of the Academy of Marketing Science, v. 23, n. 4, 1995.

12. Idem, ibidem.

13. BERRY, Leonard T. Relationship marketing of services: growing interest, emerging perspectives. Joumal of the Academy of Marketing Science, v. 23, n. 4, 1995.

14. BITNER, Mary Jo. Building service relationships: it's all about promises. Journal of the Academy of Marketing Science, v. 23, n. $4,1995$.

15. PARASURAMAN, L. B. BERRY, L. L. Serviços de marketing. competindo através da qualidade. São Paulo: Maltese-Norma, 1992.

16. PARASURAMAN, L. B. ZEITHML, V. A., BERRY, L. L. A conceptual model of service quality and its implications for future research. Joumal of marketing, v. 49, pp. 41-50, 1985.

Paulo Eduardo Saliby é aluno do curso de graduação em Administração de Empresas da EAESP/FGV.

Este texto foi um dos vencedores do $1^{\circ}$ Prêmio Empresa Júnior- EAESP/FGVRio-Sul de Gestão Empresarial, cujo prêmio foi sua publicação na $R A E$ Revista de Administração de Empresas. 